\title{
Predicting Growth Components - Unemployment, Housing Prices and Consumption Using Both Government and Corporate Yield Curves
}

\author{
Dan Saar ${ }^{1} \&$ Yossi Yagil ${ }^{1}$ \\ ${ }^{1}$ University of Haifa, Haifa, Israel \\ Correspondence: Yossi Yagil, University of Haifa, Haifa, Israel. E-mail: dsaar02@ campus.haifa.ac.il; \\ yagil@gsb.haifa.ac.il
}

Received: April 3, 2018

Accepted: May 21, 2018

Online Published: May 25, 2018

doi:10.5539/ijef.v10n6p180

URL: https://doi.org/10.5539/ijef.v10n6p180

\begin{abstract}
In this study, we predict changes in specific segments of economic growth including the unemployment rate, the housing prices and changes in personal consumption by employing corporate and government bonds. Our hypothesis is that the use of yield curves of corporate bonds will improve the predictions over previous models that used only the yield curves of government bonds. Our results support that contention. We find that corporate bonds' spreads actually help predicting the changes in both the unemployment rate and housing prices. We also find a significant positive relationship between bond spreads and future changes in personal consumption levels, but the results are weaker than in the other two segments. One additional finding worth noting is that government bonds are better predictors for the long-term, whereas corporate bonds are better indicators for the short-term.
\end{abstract}

Keywords: bond yields, housing prices, unemployment rates, consumption, forecasting, corporate bonds

\section{Introduction}

High unemployment is one of the major concerns of central banks and economic policy makers. Since the reduction of the US interest rate to its lowest level ever following the market crash of 2008, several Federal Reserve chairmen have used the unemployment rate as an indicator for timing a possible return to higher interest rates in the belief that a low level of unemployment implies a stronger economy. Past research by Estrella and Hardouvelis (1991) indicated that government bonds' yield curve could provide predictions of future economic behavior because the yield curve implies future levels of interest rates. Their work established a positive relationship between the slope of the yield curve and the expected growth rate of the economy. Saar and Yagil (2015) later refined and extended this approach by adding yield curves of corporate bonds, thereby including all segments of the credit markets.

In this paper, we use the yield curves of both government and corporate bonds to determine whether they enable us to forecast specific characteristics of growth that Estrella and Hardouvelis had trouble predicting using only the yield curve of government bonds. These characteristics include the unemployment rate, home prices, which are sensitive to changes in interest rates and the economic outlook, and personal consumption, whose growth is usually used to measure both the strength of the economy and the overall sentiment.

We hypothesize that using more segments of the credit markets by differentiating between government bonds yield spreads and corporate yield spreads provides us with a better ability to predict specific aspects of growth measured by the indicators discussed above. Our results, shown later in this study, support our hypothesis.

Previous studies that tested how the government yield curve behaves include those of Brandt and Kavajecz (2004), Berardi and Torous (2005), Chun (2011), Duffee and Hopkins (2011), Goyenko et al. (2011), Lettau and Wachter (2011) and Kim and Orphanides (2012). As explained above, our research is based on the works of Saar and Yagil $(2015 \mathrm{a}, 2015 \mathrm{~b}, 2015 \mathrm{c})$ that extended prior works by adding corporate yield curves to the analysis. This addition enables us to employ data from the entire credit market in order to achieve more refined results when predicting segment-specific parameters such as home prices, unemployment rate and consumption levels, thereby overcoming difficulties encountered in earlier studies. Additional papers that tested corporate bonds' behavior include those of Altman (1987), Fons (1994), Jarrow et al. (1997), Duffie and Singleton (1999), Helwege and Turner (1999), Zhou (2001), Huang and Huang (2012) and Bar-Isaac and Shapiro (2013).

In order to formulate our hypotheses, we also examined papers explaining the behavior of our dependent variables, including papers in the fields of unemployment, real estate and personal consumption such as those by 
Stevenson and Pellatt (1972), Kau and Keenan (1980), Harvey (1998), Papell et al. (2000), Boyd et al. (2005), Wachter (2006), Piazzesia et al. (2007), Chang et al. (2011) and Chen and Zhang (2011). These studies helped in understanding how the tested variables in our paper behave. We find that by using data about the yield curves of corporate bonds, we can improve the forecast of the parameters of specific segments of economic growth such as the Case-Shiller home prices index, and changes in the unemployment rate and personal consumption.

The paper is divided into the following sections. Section 2 discusses the theory behind our work. Section 3 describes the parameters and the data we employed in the study. Section 4 investigates whether yield curves of corporate bonds can be helpful when predicting changes in unemployment. Section 5 examines whether corporate bonds' yield curves can forecast housing price changes. Section 6 attempts to predict levels of personal consumption by using data on yield curves. Finally, Section 7 concludes the study.

\section{Theoretical Background}

Since the 2008 crisis, several Federal Reserve chairmen have associated the return to "normal" interest rates with the behavior of the labor market and a low level of unemployment. This association stems from the fact that low unemployment usually indicates a stronger economy that can sustain a hike in interest rates. In this scenario, long-term bonds will provide higher yields because long-term interest rates will probably be higher than current rates. Thus, it is plausible to assume that a connection exists between bond yields and macroeconomic parameters.

Indeed, led by Estrella and Hardouvelis, previous studies have established the relationship between the yield curve of government bonds and macroeconomic parameters that predict economic growth. The researchers demonstrate that the slope of the yield curve of government bonds, denoted as the spread between long-term yields and short-term yields, has a positive relationship with future growth.

Nevertheless, researchers have found it difficult to predict specific segments of economic growth such as personal consumption. We believe that these difficulties stem from the use of only some of the components of the credit market. Recent studies by Saar and Yagil employed the corporate yield curve as an explanatory variable as well, thereby using the entire credit market in successfully forecasting economic behavior and even specific sector behavior. We test our hypotheses formulated later in this study using data from the US market from October 2002 to December 2016.

Thus, by employing both the government and corporate yield curves, and due to the relationship between future interest rates and our explained variables including the unemployment rate, housing prices and personal consumption, we claim that yield curves can also help forecasting specific segments of economic growth. Our results, shown later in this study, support our argument. While one could argue that other parameters might affect our explained variables, the main focus of the paper is to check whether the yield spreads of corporate and government bonds can help in predicting future behavior of specific segments of the economy.

\section{Data Description}

\subsection{Data}

In our study, we use the composite yield curves of corporate and government bonds. Our data source is Bloomberg, considered one of the most advanced data suppliers, providing both reliable and consistent data from October 2002 to December 2016. The curves we use are perceived as option-free because they consist of make-whole callable bonds alone, which eliminate prepayment risks (Fabozzi, 2005). This type of callable bonds eliminate the prepayment risk because the call involves an additional payment.

In accordance with Chun (2011), to achieve continuous results, we collected daily yield curve data and calculated the average for each month. Table 1 includes statistical information regarding the variables we used most in this paper.

Table 1. Descriptive statistics of bond yields and macroeconomic parameters

\begin{tabular}{lccccc}
\hline & $\mathrm{N}$ & Minimum & Maximum & Mean & Std. Deviation \\
\hline Spread(G) (\%) & 171 & -0.478 & 3.703 & 2.049 & 1.078 \\
Spread(A) (\%) & 171 & -0.252 & 1.124 & 0.592 & 0.331 \\
Spread(BBB) (\%) & 171 & -0.500 & 0.408 & 0.073 & 0.200 \\
Unemployment (\%) & 171 & 4.400 & 10.000 & 6.502 & 1.749 \\
Case-Shiller Home Prices Index & 171 & 133.550 & 206.520 & 166.072 & 22.584 \\
Personal Consumption Exp. (Bil. \$) & 171 & 7,469 & 12,457 & 10,234 & 1,476 \\
\hline
\end{tabular}

Note. Data was collected using Bloomberg's fair market option-free yield curves. The data is available from 2002 to 2016 for most bonds. The spreads denoted in the table are the most relevant bond spreads used in the study. 


\subsection{Methodology}

Through regression models, we utilize bond spreads to predict specific economic indicators such as the unemployment rate, housing prices and personal consumption.

The following are the explanatory variables we use in our models:

Spread(G) is the yield spread on US government bonds. It is defined as the difference between the yield to maturity of a 10-year government bond $\left(\mathrm{Y}(\mathrm{G})_{(10 \mathrm{Yr}}\right)$ and a 3-month government bond $\left(\mathrm{Y}(\mathrm{G})_{(0.25 \mathrm{Yr})}\right)$ :

$$
\operatorname{Spread}(G)=Y(G)_{(10 Y r)}-Y(G)_{(0.25 Y r)} \text {. }
$$

In order to distinguish between the predictive ability of the yield spread on US government bonds and that of corporate bonds, we also calculate these parameters:

TotSpread(A) is calculated by subtracting the yield to maturity on 3-month A-rated corporate bonds from the yield to maturity on 10-year A-rated corporate bonds. As a result, the A TotSpead is:

$$
\text { TotSpread }(A)=Y(A)_{(10 Y r)}-Y(A)_{(0.25 Y r)} .
$$

MarSpread(A) is calculated by subtracting the Totalspread of bonds with a rating that is one level higher from the TotSpread of the investigated rating. This variable enables us to neutralize the effect of higher rated bonds. For example, the marginal spread on A-rated bonds is as follows:

$$
\operatorname{MarSpread}(A)=\operatorname{TotSpread}(A)-\operatorname{Spread}(G) \text {. }
$$

These variables are consistent with those that Saar and Yagil used in extending previous studies.

Data for the AA rating is only available until 2011. As a result, we use A as the highest corporate bond rating. When making our initial adjustments, we also tested AA data until 2011 and found similar results. This phase demonstrates the robustness of our results shown later in this study.

In order to check the effect of explanatory variables of time $t$ (the current time) on macroeconomic parameters at time $\mathrm{t}+\mathrm{k}$ we lag the explanatory variables by $\mathrm{k}$ which is the prediction horizon.

Using this method, we can investigate whether the explanatory variables actually help forecasting specific future economic indicators. In our study, we use forecasting horizons of 1 to 36 months to check both short-term and long-term predictions. By using monthly data, we achieve more accurate results than previous papers that usually use quarterly data.

\section{Can Corporate and Government Yield Curves Forecast Changes in Unemployment?}

We argue that using the entire credit market by considering both the corporate bonds' and government bonds' yield curves we can improve the prediction of unemployment rates. Thus, we posit that:

H1: Employing corporate and government yield curves allows us to forecast upcoming changes in unemployment.

\subsection{Definitions}

The first explained variable defined in this section is UnemploymentChg, which is the percentage monthly change in the unemployment rate. This variable enables to investigate whether the explanatory variables can predict a specific percentage change in unemployment.

The second variable in this section is a dummy parameter that gets the value 1 if the unemployment rate declined in the current month, and 0 otherwise. This variable indicates whether the state of the labor market has improved or deteriorated.

\subsection{Testing the Hypothesis: Estimated Equations and Findings for HI}

Past papers indicated that employing the corporate yield curves as financial predictors can improve GDP predictions. We suggest that the addition of corporate yield curves can also assist us in predicting specific segments of economic growth such as labor market trends. The equation (Eq. 4), strives to forecast the monthly change in unemployment by using the spreads defined above:

$$
\text { UnemploymentChg }{ }_{t+k}=\beta_{0}+\beta_{1} \operatorname{Spread}(G)_{t}+\beta_{2} \operatorname{MarSpread}(A)_{t}+\varepsilon_{t},
$$

where, UnemploymentChg $g_{t+k}$ is the monthly percentage change in unemployment. 
Table 2. Predicted monthly changes in the US unemployment rate based on US government spreads and marginal spreads of A-Rated US corporate bonds, 10/2002 - 12/2016

\begin{tabular}{ccccccccccc}
\hline $\mathrm{k}$ & $\beta_{0}$ & $\mathrm{t}_{\beta 0}$ & $\beta_{1}$ & $\mathrm{t}_{\beta 1}$ & $\beta_{2}$ & $\mathrm{t}_{\beta 2}$ & $\mathrm{R}^{2}$ & $\mathrm{~F}$ & Sig. & $\mathrm{n}$ \\
\hline 1 & 0.012 & 2.354 & 0.003 & 1.743 & -0.033 & -4.923 & 0.165 & 12.126 & 0.000 & 170 \\
3 & 0.015 & 3.097 & 0.002 & 1.367 & -0.035 & -4.892 & 0.185 & 12.762 & 0.000 & 168 \\
6 & 0.018 & 2.908 & 0.000 & 0.020 & -0.032 & -3.858 & 0.164 & 9.062 & 0.000 & 165 \\
9 & 0.022 & 2.558 & -0.003 & -1.450 & -0.031 & -2.745 & 0.188 & 6.345 & 0.002 & 162 \\
12 & 0.024 & 2.278 & -0.005 & -2.323 & -0.027 & -2.366 & 0.194 & 4.729 & 0.010 & 159 \\
15 & 0.027 & 2.349 & -0.007 & -2.607 & -0.022 & -2.618 & 0.208 & 4.499 & 0.013 & 156 \\
18 & 0.027 & 2.904 & -0.009 & -3.124 & -0.015 & -2.443 & 0.228 & 6.805 & 0.001 & 153 \\
21 & 0.027 & 3.785 & -0.010 & -3.137 & -0.011 & -1.711 & 0.246 & 11.183 & 0.000 & 150 \\
24 & 0.026 & 3.843 & -0.010 & -3.266 & -0.009 & -1.007 & 0.234 & 9.943 & 0.000 & 147 \\
30 & 0.023 & 2.429 & -0.009 & -3.375 & -0.007 & -0.838 & 0.184 & 6.259 & 0.003 & 141 \\
36 & 0.018 & 1.449 & -0.006 & -3.108 & -0.009 & -0.805 & 0.106 & 4.876 & 0.009 & 135 \\
\hline
\end{tabular}

Note. Estimated model, Eq. 4: UnemploymentChg $g_{t+k}=\beta_{0}+\beta_{1}$ Spread $(G)_{t}+\beta_{2}$ MarSpread $\left.A\right)_{t}+\varepsilon_{t}$, where UnemploymentChg is the monthly percentage change in the US unemployment $\operatorname{rate}, \operatorname{Spread}(\mathrm{G})$ is the US government yield spread, defined as the difference between the yield to maturity of a 10-year government bond $(\mathrm{Y}(\mathrm{G})(10 \mathrm{Yr}))$ and a 3-month government bond $(\mathrm{Y}(\mathrm{G})(0.25 \mathrm{Yr}))$ and $\mathrm{MarSpread}(\mathrm{A})$ is the marginal corporate yield spread calculated by: MarSpread $A)=\operatorname{Tot} \operatorname{Spread} A)-\operatorname{Spread}(G)$

The correlation between $\operatorname{Spread}(\mathrm{G})$ and $\operatorname{MarSpread}(\mathrm{A})$ is 0.24 .

Table 2 presents the findings for Eq. 4. When we estimate an OLS regression, the lagging of the data creates a moving average error of order k-1. In order to correct this error, we used the Newey-West method which enables to adjust the created errors by using the lag length of k-1 due to the error that was created.

The results of this regression indicate that the yield curves can forecast monthly movements in the US unemployment rate, because the regression equation is significant for all forecasting horizons. There is a significant negative relationship between the yield curve spreads and a rise in unemployment. In other words, when the spreads increase, the future unemployment rate is expected to be lower. The results we find are in line with our assumptions, because, as explained in the theoretical background section of the study, wider spreads are related to higher future growth, indicating lower unemployment. Another interesting finding that accords with Saar and Yagil's previous results is that corporate bond spreads are better at predicting short-term macroeconomic parameters, whereas government bond spreads are better at predicting long-term macroeconomic parameters.

To test our hypothesis further, we extend the previous equation to the following:

$$
\text { UnemploymentChg } g_{t+k}=\beta_{0}+\beta_{1} \operatorname{Spread}(G)_{t}+\beta_{2} \operatorname{MarSpread}(I G)_{t}+\beta_{3} \operatorname{MarSpread}(H Y)_{t}+\varepsilon_{t} \text {. }
$$

This equation considers the entire credit market, dividing it into three commonly used categories: government bonds, investment grade bonds (rated A and BBB) and high yield bonds (rated BB and B). We believe that by using the entire credit market we can achieve the most accurate results.

Table 3. Predicted monthly changes in the US unemployment rate based on US government spreads and marginal spreads of investment grade US corporate bonds rated A and BBB, and high yield US corporate bonds rated $\mathrm{BB}$ and $\mathrm{B}, 10 / 2002-12 / 2016$

\begin{tabular}{ccccccccccccc}
\hline $\mathrm{k}$ & $\beta_{0}$ & $\mathrm{t}_{\beta 0}$ & $\beta_{1}$ & $\mathrm{t}_{\beta 1}$ & $\beta_{2}$ & $\mathrm{t}_{\beta 2}$ & $\beta_{3}$ & $\mathrm{t}_{\beta 3}$ & $\mathrm{R}^{2}$ & $\mathrm{~F}$ & Sig. & $\mathrm{n}$ \\
\hline 1 & 0.024 & -1.425 & -0.001 & -0.356 & -0.038 & -4.619 & -0.002 & -1.425 & 0.209 & 9.801 & 0.000 & 170 \\
3 & 0.026 & -1.575 & -0.002 & -1.075 & -0.038 & -4.495 & -0.002 & -1.575 & 0.213 & 9.569 & 0.000 & 168 \\
6 & 0.030 & -2.057 & -0.004 & -2.930 & -0.039 & -4.032 & -0.003 & -2.057 & 0.202 & 9.618 & 0.000 & 165 \\
9 & 0.034 & -1.337 & -0.006 & -3.834 & -0.038 & -2.843 & -0.002 & -1.337 & 0.240 & 7.784 & 0.000 & 162 \\
12 & 0.037 & -1.564 & -0.008 & -3.639 & -0.036 & -3.056 & -0.002 & -1.564 & 0.260 & 6.393 & 0.000 & 159 \\
15 & 0.033 & -0.443 & -0.009 & -3.084 & -0.024 & -2.538 & -0.001 & -0.443 & 0.233 & 5.007 & 0.002 & 156 \\
18 & 0.031 & 0.524 & -0.010 & -3.967 & -0.017 & -2.682 & 0.001 & 0.524 & 0.258 & 8.014 & 0.000 & 153 \\
21 & 0.029 & 0.868 & -0.011 & -4.528 & -0.010 & -1.269 & 0.001 & 0.868 & 0.265 & 11.136 & 0.000 & 150 \\
24 & 0.024 & 1.278 & -0.010 & -4.517 & -0.003 & -0.365 & 0.002 & 1.278 & 0.248 & 7.914 & 0.000 & 147 \\
30 & 0.021 & 0.801 & -0.009 & -3.684 & -0.002 & -0.213 & 0.002 & 0.801 & 0.190 & 4.843 & 0.003 & 141 \\
36 & 0.012 & 0.690 & -0.006 & -2.469 & 0.003 & 0.260 & 0.002 & 0.690 & 0.099 & 3.169 & 0.027 & 135 \\
\hline
\end{tabular}

Note. Estimated model, Eq. 5: UnemploymentChg $g_{t+k}=\beta_{0}+\beta_{1}$ Spread $(G)_{t}+\beta_{2}$ MarSpread $(G)_{t}+\beta_{3}$ MarSpread $\left.H Y\right)_{t}+\varepsilon_{t}$, where UnemploymentChg is the monthly percentage change in the US unemployment $\operatorname{rate}, \operatorname{Spread}(\mathrm{G})$ is the US government yield spread, defined as the difference between the yield to maturity of a 10-year government bond $\left(\mathrm{Y}(\mathrm{G})_{(10 \mathrm{Yr})}\right)$ and a 3-month government bond $\left(\mathrm{Y}(\mathrm{G})_{(0.25 \mathrm{Yr})}\right)$, MarSpread(IG) and MarSpread(HY) are the marginal investment grade and high yield spreads calculated by:

MarSpread $(G)=$ TotSpread $(G)-$ Spread $(G)$ MarSpread $(H Y)=$ TotSpread $(H Y)-$ TotSpread $(G)$

The correlation coefficients for the three explanatory variables are: $-0.05,-0.19,-0.69$ for the following three pair correlations, respectively: Spread(G)-MarSpread(IG),Spread(G)-MarSpread(HY) and MarSpread(IG)-MarSpread(HY). 
Indeed, the findings in Table 3 illustrate that the addition of high yield bonds improves the prediction of changes in the unemployment rate. This table also shows a negative relationship between the spreads and the changes in unemployment. However, an interesting phenomenon appears as the prediction value of high yield bonds is not significant for most forecasting horizons. The comparison between Tables 2 and 3 indicates that using the entire credit market improves the prediction, because the significance of the regression is stronger for most forecasting horizons. In addition, as we saw earlier, government bonds are predicting better for long-term predictions as opposed to corporate bonds that are better for short-term forecasting.

These results confirm H1, because we demonstrate that the yield curve spreads can forecast movements in unemployment. As we explained earlier, investors think that the Federal Reserve will increase interest rates when the economy is expected to improve (meaning a lower unemployment rate), and their expectations steepen the yield curves. On the contrary, when the economy is in distress, the Federal Reserve is expected to lower rates flattening the curves. By using the slopes of the curves of the entire credit market, we use the basic yield levels that are implicit in the slopes.

Our final regression in this section attempts to predict whether the unemployment rate declines in the subsequent month:

$$
\text { UnemploymentDec }_{t+k}=\frac{e^{\left.\left(\beta_{0}+\beta_{1} \operatorname{Spread}(G)_{t}+\beta_{2} \text { MarSpread } A\right)_{t}+\varepsilon_{t}\right)}}{e^{\left.\left(\beta_{0}+\beta_{1} \operatorname{Spread}(G)_{t}+\beta_{2} \text { MarSpread } A\right)_{t}+\varepsilon_{t}\right)}+1} .
$$

Table 4. Predicted monthly decrease in the US unemployment rate based on US government spreads and marginal spreads of A-Rated US corporate bonds, 10/2002 - 12/2016

\begin{tabular}{ccccccccccc}
\hline $\mathrm{k}$ & $\beta_{0}$ & Wald $_{\beta 0}$ & $\beta_{1}$ & Wald $_{\beta 1}$ & $\beta_{2}$ & Wald $_{\beta 2}$ & Cox\&SnellR $^{2}$ & Chi $^{2}$ & Sig. & $\mathrm{n}$ \\
\hline 1 & -0.808 & -1.947 & -0.139 & -0.914 & 1.252 & 2.382 & 0.027 & 6.197 & 0.045 & 170 \\
3 & -0.996 & -2.342 & -0.128 & -0.838 & 1.551 & 2.863 & 0.040 & 9.091 & 0.011 & 168 \\
6 & -1.155 & -2.675 & -0.002 & -0.012 & 1.400 & 2.637 & 0.036 & 8.038 & 0.018 & 165 \\
9 & -1.332 & -3.020 & 0.069 & 0.438 & 1.504 & 2.809 & 0.046 & 10.113 & 0.006 & 162 \\
12 & -1.443 & -3.222 & 0.142 & 0.889 & 1.411 & 2.630 & 0.047 & 10.240 & 0.006 & 159 \\
15 & -1.496 & -3.308 & 0.143 & 0.889 & 1.427 & 2.623 & 0.048 & 10.263 & 0.006 & 156 \\
18 & -1.533 & -3.354 & 0.289 & 1.761 & 0.984 & 1.878 & 0.045 & 9.282 & 0.010 & 153 \\
21 & -1.646 & -3.506 & 0.393 & 2.326 & 0.803 & 1.549 & 0.053 & 10.885 & 0.004 & 150 \\
24 & -1.476 & -3.203 & 0.383 & 2.290 & 0.518 & 1.015 & 0.042 & 8.436 & 0.015 & 147 \\
30 & -1.417 & -3.050 & 0.462 & 2.706 & 0.103 & 0.203 & 0.047 & 8.960 & 0.011 & 141 \\
36 & -1.207 & -2.683 & 0.389 & 2.342 & 0.007 & 0.014 & 0.034 & 6.280 & 0.043 & 135 \\
\hline
\end{tabular}

Note. Estimated model, Eq. 6: UnemploymentDec $t_{t+k}=\frac{e^{\left.\left(\beta_{0}+\beta_{1} \text { Spread }(G)_{t}+\beta_{2} \text { MarSpread } A\right)_{t}+\varepsilon_{t}\right)}}{e^{\left.\left(\beta_{0}+\beta_{1} \text { Spread }(G)_{t}+\beta_{2} \text { MarSpread } A\right)_{t}+\varepsilon_{t}\right)}+1}$, where UnemploymentDec receives the

value of 1 when the unemployment rate in the current month is lower than that of the previous month, and 0 otherwise. $\operatorname{Spread}(G)$ is the

US government yield spread, defined as the difference between the yield to maturity of a 10-year government bond $\left(\mathrm{Y}(\mathrm{G})_{(10 \mathrm{Yr})}\right)$ and a

3-month government bond $\left(\mathrm{Y}(\mathrm{G})_{(0.25 \mathrm{Yr})}\right)$ and $\operatorname{MarSpread}(\mathrm{A})$ is the marginal corporate yield spread calculated by:

$\operatorname{MarSpread}(A)=\operatorname{Tot} \operatorname{Spread}(A)-\operatorname{Spread}(G)$

The correlation between $\operatorname{Spread}(\mathrm{G})$ and $\operatorname{MarSpread}(\mathrm{A})$ is 0.24 .

The results presented in Table 4 indicate that the yield curve spreads can actually forecast a decline in unemployment. We should note that for this regression the connection between the explanatory and explained variables is positive, because in contrast to the previous regressions, here the explained variable serves as a good sign for the economy, reflecting a decrease in unemployment. The previous findings about the use of yield curves of government bonds for long-term predictions and the use of yield curves of corporate bonds for short-term predictions are evident here as well.

In order to validate our results even further we performed an out-of-sample analysis of the first linear regressions we estimated in this paper. To conduct such an analysis, we first had to define a proper estimation period which was defined from the starting point until the end of 2010 while the other observations were defined as the prediction period. Using this method we can compare our model's forecasts with the real data from the prediction period. The out-of-sample analysis for this section is presented in Figure 1. 


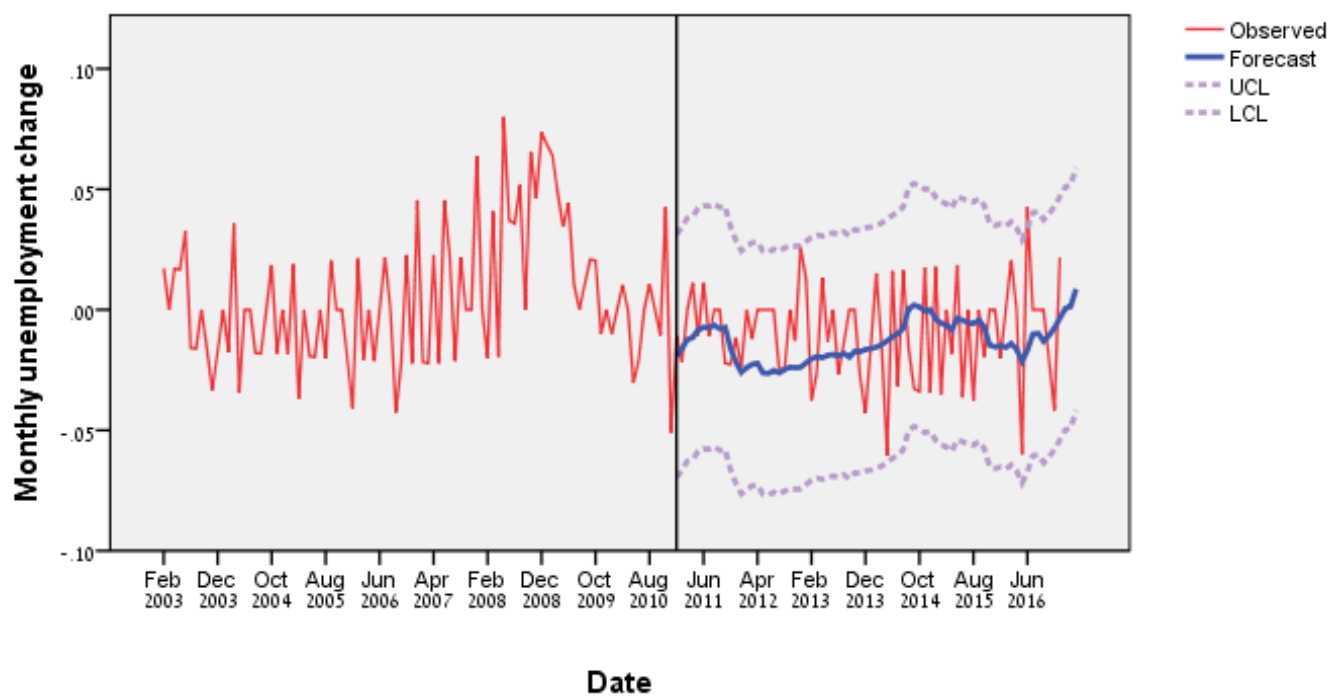

Figure 1. Out-of-sample forecasted monthly changes in US unemployment rate based on US government spreads and marginal spreads of A-Rated US corporate bonds, 10/2002 - 12/2016

\begin{tabular}{|c|c|c|c|c|c|c|}
\hline \multirow[b]{2}{*}{ Model } & \multirow{2}{*}{$\begin{array}{l}\text { Number of } \\
\text { Predictors }\end{array}$} & \multirow{2}{*}{$\begin{array}{c}\text { Model Fit statistics } \\
\text { Stationary R-squared }\end{array}$} & \multicolumn{3}{|c|}{ Ljung-Box Q(18) } & \multirow[b]{2}{*}{ Number of Outliers } \\
\hline & & & Statistics & DF & Sig. & \\
\hline UemploymentChg & 2 & 0.215 & 37.227 & 18 & 0.005 & 0 \\
\hline
\end{tabular}

This analysis yields a very small RMSE, cementing the effective prediction of the future unemployment rate. The various different tools we use indicate the robustness of our results which confirms our first hypothesis stating that corporate and government spreads can forecast future changes in unemployment.

\section{Predicting Changes in Housing Prices Using Spreads of Government and Corporate Bonds}

Turning to the real estate market, we now try to forecast future changes in housing prices. Although low interest rates are correlated with high housing prices, we suggest that larger spreads indicating a future rise in interest rates foretell an upcoming rise in housing prices because of the improvement of the economy and the increase in disposable income. Thus, we posit that:

$\mathrm{H} 2$ : Higher corporate and government bond spreads indicate an upcoming rise in housing prices.

\subsection{Definitions}

In order to measure housing prices, we use the S\&P/Case-Shiller Home Prices Index, which is a commonly used proxy for measuring housing prices.

The first explained variable defined in this section is CaseShillerYoYChg, which is the percentage yearly change in the Case-Shiller Index. This variable allows us to investigate whether the explanatory variables can predict a specific percentage change in housing prices. The second variable in this section is CaseShillerMoMChg indicating the monthly change in the Case-Shiller Index. The last variable we define for this section is a parameter that gets the value 1 when the Case-Shiller Index rises in the current month compared with the corresponding month in the previous year. This variable indicates if the housing market has improved or deteriorated.

\subsection{Testing the Hypothesis: Estimated Equations and Findings for $\mathrm{H} 2$}

The first regression equation (Eq. 7) in this section attempts to predict the yearly change in housing prices by using the government spread and the marginal spread:

$$
\text { CaseShillerYoYChg }{ }_{t+k}=\beta_{0}+\beta_{1} \operatorname{Spread}(G)_{t}+\beta_{2} \operatorname{MarSpread}(A)_{t}+\varepsilon_{t} .
$$


Table 5. Predicted yearly changes in the S\&P/case-shiller home prices index based on US government spreads and marginal spreads of A-Rated US corporate bonds, 10/2002 - 12/2016

\begin{tabular}{ccccccccccc}
\hline $\mathrm{k}$ & $\beta_{0}$ & $\mathrm{t}_{\beta 0}$ & $\beta_{1}$ & $\mathrm{t}_{\beta 1}$ & $\beta_{2}$ & $\mathrm{t}_{\beta 2}$ & $\mathrm{R}^{2}$ & $\mathrm{~F}$ & Sig. & $\mathrm{n}$ \\
\hline 1 & -0.043 & -2.688 & -0.010 & -1.732 & 0.128 & 5.650 & 0.190 & 15.997 & 0.000 & 170 \\
3 & -0.062 & -2.167 & -0.003 & -0.353 & 0.134 & 3.603 & 0.215 & 6.654 & 0.002 & 168 \\
6 & -0.082 & -2.011 & 0.007 & 0.548 & 0.133 & 2.804 & 0.242 & 4.178 & 0.017 & 165 \\
9 & -0.100 & -2.023 & 0.018 & 1.211 & 0.122 & 2.413 & 0.270 & 3.321 & 0.039 & 162 \\
12 & -0.115 & -2.180 & 0.028 & 1.698 & 0.110 & 2.173 & 0.316 & 3.117 & 0.047 & 159 \\
15 & -0.129 & -2.526 & 0.037 & 2.104 & 0.096 & 2.132 & 0.379 & 3.482 & 0.033 & 156 \\
18 & -0.142 & -3.310 & 0.045 & 2.446 & 0.088 & 2.353 & 0.464 & 4.846 & 0.009 & 153 \\
21 & -0.152 & -4.525 & 0.049 & 2.688 & 0.088 & 2.816 & 0.534 & 8.049 & 0.000 & 150 \\
24 & -0.158 & -5.350 & 0.050 & 2.958 & 0.089 & 2.789 & 0.579 & 11.363 & 0.000 & 147 \\
30 & -0.155 & -3.489 & 0.042 & 3.200 & 0.107 & 3.029 & 0.559 & 8.181 & 0.000 & 141 \\
36 & -0.144 & -2.935 & 0.028 & 3.175 & 0.131 & 4.043 & 0.501 & 8.199 & 0.000 & 135 \\
\hline
\end{tabular}

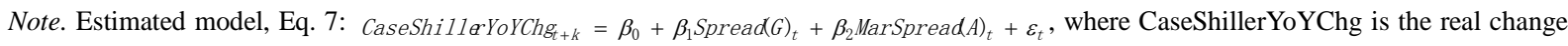
in the Case-Shiller Index compared with the corresponding month in the previous year. $\operatorname{Spread}(\mathrm{G})$ is the US government yield spread, defined as the difference between the yield to maturity of a 10-year government bond $\left(\mathrm{Y}(\mathrm{G})_{(10 \mathrm{Yr})}\right)$ and a 3-month government bond $\left(\mathrm{Y}(\mathrm{G})_{(0.25 \mathrm{Yr})}\right)$ and MarSpread(A) is the marginal corporate yield spread calculated by: $\operatorname{MarSpread}(A)=\operatorname{TotSpread}(A)-\operatorname{Spread}(G)$

The correlation between $\operatorname{Spread}(\mathrm{G})$ and $\operatorname{MarSpread}(\mathrm{A})$ is 0.24 .

The results for this equation are shown in Table 5, which indicates that the regression is significant for all of the forecasted horizons. As suspected, we found a significant positive relationship between yield curve spreads and a rise in housing prices. This finding is in line with our contention discussed above, because larger spreads are related to higher future growth, indicating that consumers have more disposable income with which to buy houses at higher prices.

Here too, we can see that corporate bonds are better at predicting short-term changes in housing prices, and government bonds are better at predicting long-term housing prices.

As we did in the previous section, to investigate our hypothesis further we extend the previous equation to the following:

$$
\text { CaseShillerYoYChg }{ }_{t+k}=\beta_{0}+\beta_{1} \operatorname{Spread}(G)_{t}+\beta_{2} \operatorname{MarSpread}(I G)_{t}+\beta_{3} \operatorname{MarSpread}(H Y)_{t}+\varepsilon_{t} \text {. }
$$

This equation reveals the predictive abilities of the entire credit market regarding future housing prices. The results shown in Table 6 reiterate the previous findings shown in Table 5.

Table 6. Predicted yearly changes in the S\&P/case-shiller home prices index based on US government spreads and marginal spreads of investment grade US corporate bonds rated A and $\mathrm{BBB}$, and high yield US corporate bonds rated $\mathrm{BB}$ and $\mathrm{B}, 10 / 2002-12 / 2016$

\begin{tabular}{ccccccccccccc}
\hline $\mathrm{k}$ & $\beta_{0}$ & $\mathrm{t}_{\beta 0}$ & $\beta_{1}$ & $\mathrm{t}_{\beta 1}$ & $\beta_{2}$ & $\mathrm{t}_{\beta 2}$ & $\beta_{3}$ & $\mathrm{t}_{\beta 3}$ & $\mathrm{R}^{2}$ & $\mathrm{~F}$ & Sig. & $\mathrm{n}$ \\
\hline 1 & -0.102 & 0.544 & 0.003 & 0.645 & 0.166 & 6.873 & 0.003 & 0.544 & 0.387 & 47.535 & 0.000 & 170 \\
3 & -0.122 & 0.294 & 0.010 & 1.203 & 0.173 & 4.504 & 0.002 & 0.294 & 0.434 & 23.366 & 0.000 & 168 \\
6 & -0.138 & -0.005 & 0.019 & 1.537 & 0.166 & 3.436 & 0.000 & -0.005 & 0.465 & 15.159 & 0.000 & 165 \\
9 & -0.147 & -0.217 & 0.027 & 1.782 & 0.149 & 2.863 & -0.003 & -0.217 & 0.479 & 10.549 & 0.000 & 162 \\
12 & -0.156 & -0.346 & 0.035 & 2.053 & 0.135 & 2.690 & -0.004 & -0.346 & 0.510 & 9.224 & 0.000 & 159 \\
15 & -0.161 & -0.507 & 0.043 & 2.385 & 0.116 & 2.731 & -0.006 & -0.507 & 0.542 & 9.735 & 0.000 & 156 \\
18 & -0.167 & -0.649 & 0.050 & 2.836 & 0.100 & 2.799 & -0.007 & -0.649 & 0.593 & 12.305 & 0.000 & 153 \\
21 & -0.169 & -0.681 & 0.054 & 3.346 & 0.087 & 2.322 & -0.006 & -0.681 & 0.615 & 15.609 & 0.000 & 150 \\
24 & -0.168 & -0.508 & 0.055 & 3.831 & 0.077 & 1.592 & -0.005 & -0.508 & 0.614 & 15.063 & 0.000 & 147 \\
30 & -0.155 & -0.177 & 0.050 & 3.529 & 0.072 & 1.186 & -0.002 & -0.177 & 0.507 & 6.858 & 0.000 & 141 \\
36 & -0.139 & 0.002 & 0.039 & 2.653 & 0.079 & 1.476 & 0.000 & 0.002 & 0.354 & 8.854 & 0.000 & 135 \\
\hline
\end{tabular}

Note. Estimated model, Eq. 8: CaseShillerYYChg $t_{t+k}=\beta_{0}+\beta_{1} \operatorname{Spread}(G)_{t}+\beta_{2}$ MarSpread $(G)_{t}+\beta_{3}$ MarSpread $\left.H Y\right)_{t}+\varepsilon_{t}$, where CaseShillerYoYChg is the real change in the Case-Shiller Index compared with the corresponding month in the previous year. Spread(G) is the US government yield spread, defined as the difference between the yield to maturity of a 10-year government bond $\left(\mathrm{Y}(\mathrm{G})_{(10 \mathrm{Yr})}\right)$ and a 3-month government bond $\left(\mathrm{Y}(\mathrm{G})_{(0.25 \mathrm{Yr})}\right)$, MarSpread $(\mathrm{IG})$ and $\operatorname{MarSpread}(\mathrm{HY})$ are the marginal investment grade and high yield spreads calculated by: $\operatorname{MarSpread}(I G)=\operatorname{TotSpread}(I G)-\operatorname{Spread}(G), \operatorname{MarSpread}(H Y)=\operatorname{TotSpread}(H Y)-\operatorname{TotSpread}(I G)$

The correlation coefficients for the three explanatory variables are: $-0.05,-0.19,-0.69$ for the following three pairs of correlations, respectively: Spread(G)-MarSpread(IG),Spread(G)-MarSpread(HY) and MarSpread(IG)-MarSpread(HY). 
Here too, Table 6 indicates that the addition of high yield bonds does not improve the prediction materially, because they do not demonstrate a significant relationship with future housing prices. In order to check our results from another angle we use the following logistic regression estimating a predicted rise in housing prices:

$$
\text { CaseShillerYoYRise } e_{t+k}=\frac{e^{\left.\left(\beta_{0}+\beta_{1} \text { Spread }(G)_{t}+\beta_{2} \text { MarSPread } A\right)_{t}+\varepsilon_{t}\right)}}{e^{\left.\left(\beta_{0}+\beta_{1} \text { Spread }(G)_{t}+\beta_{2} \text { MarSpread } A\right)_{t}+\varepsilon_{t}\right)}+1} .
$$

Table 7. Predicted yearly increases in the S\&P/case-shiller home prices index based on US government spreads and marginal spreads of A-Rated US corporate bonds, 10/2002 - 12/2016

\begin{tabular}{ccccccccccc}
\hline $\mathrm{k}$ & $\beta_{0}$ & Wald $_{\beta 0}$ & $\beta_{1}$ & Wald $_{\beta 1}$ & $\beta_{2}$ & Wald $_{\beta 2}$ & Cox\&SnellR $^{2}$ & Chi $^{2}$ & Sig. & $\mathrm{n}$ \\
\hline 1 & -0.249 & -0.610 & -0.099 & -0.648 & 1.703 & 3.233 & 0.051 & 11.337 & 0.003 & 170 \\
3 & -0.606 & -1.475 & 0.009 & 0.060 & 1.907 & 3.550 & 0.067 & 14.888 & 0.001 & 168 \\
6 & -1.075 & -2.532 & 0.117 & 0.751 & 2.301 & 4.083 & 0.104 & 22.859 & 0.000 & 165 \\
9 & -1.339 & -3.096 & 0.257 & 1.622 & 2.213 & 3.950 & 0.118 & 25.480 & 0.000 & 162 \\
12 & -1.506 & -3.421 & 0.374 & 2.294 & 2.042 & 3.666 & 0.126 & 26.883 & 0.000 & 159 \\
15 & -1.690 & -3.731 & 0.494 & 2.933 & 1.877 & 3.391 & 0.139 & 29.327 & 0.000 & 156 \\
18 & -2.336 & -4.603 & 0.699 & 3.748 & 2.213 & 3.793 & 0.212 & 43.911 & 0.000 & 153 \\
21 & -3.137 & -5.325 & 0.796 & 3.842 & 3.208 & 4.776 & 0.313 & 63.934 & 0.000 & 150 \\
24 & -3.467 & -5.538 & 0.768 & 3.608 & 3.815 & 5.152 & 0.359 & 72.089 & 0.000 & 147 \\
30 & -3.392 & -5.601 & 0.486 & 2.486 & 4.594 & 5.442 & 0.372 & 72.190 & 0.000 & 141 \\
36 & -5.816 & -5.353 & -0.029 & -0.131 & 10.906 & 4.868 & 0.608 & 113.491 & 0.000 & 135 \\
\hline
\end{tabular}

Note. Estimated model, Eq. 9: CaseShillerYoYRise $e_{t+k}=\frac{e^{\left.\left(\beta_{0}+\beta_{1} \text { Spread }(G)_{t}+\beta_{2} \text { MarSpread } A\right)_{t}+\varepsilon_{t}\right)}}{e^{\left.\left(\beta_{0}+\beta_{1} \text { Spread }(G)_{t}+\beta_{2} \text { MarSpread } A\right)_{t}+\varepsilon_{t}\right)}+1}$, where CaseShillerYoYRise receives the value of 1

when the Case-Shiller Index value in the current month is higher than that of the corresponding month in the previous year, and 0 otherwise. $\operatorname{Spread}(\mathrm{G})$ is the US government yield spread, defined as the difference between the yield to maturity of a 10-year government bond $\left(\mathrm{Y}(\mathrm{G})_{(10 \mathrm{Yr})}\right)$ and a 3-month government bond $\left(\mathrm{Y}(\mathrm{G})_{(0.25 \mathrm{Yr})}\right)$ and MarSpread(A) is the marginal corporate yield spread calculated by: $\operatorname{MarSpread}(A)=\operatorname{TotSpread}(A)-\operatorname{Spread}(G)$

The correlation between $\operatorname{Spread}(\mathrm{G})$ and $\operatorname{MarSpread}(\mathrm{A})$ is 0.24 .

The results presented in Table 7 confirm our previous findings showing that government and corporate bond spreads can predict a rise in housing prices. The regression is significant for all forecasting horizons, indicating a very strong relationship between government and corporate bond spreads and a rise in the Case-Shiller Index.

The final regression we estimate in this section tests the predictive ability of the spreads when forecasting monthly changes in the housing price index rather than yearly changes tested so far in this study:

$$
\text { CaseShillerMoMChg }{ }_{t+k}=\beta_{0}+\beta_{1} \operatorname{Spread}(G)_{t}+\beta_{2} \operatorname{MarSpread}(A)_{t}+\varepsilon_{t} \text {. }
$$

Table 8. Predicted monthly changes in the S\&P/Case-Shiller Home Prices Index Based on US Government Spreads and Marginal Spreads of A-Rated US Corporate Bonds, 10/2002 - 12/2016

\begin{tabular}{ccccccccccc}
\hline $\mathrm{k}$ & $\beta_{0}$ & $\mathrm{t}_{\beta 0}$ & $\beta_{1}$ & $\mathrm{t}_{\beta 1}$ & $\beta_{2}$ & $\mathrm{t}_{\beta 2}$ & $\mathrm{R}^{2}$ & $\mathrm{~F}$ & Sig. & $\mathrm{n}$ \\
\hline 1 & -0.009 & -4.337 & 0.001 & 1.535 & 0.012 & 4.037 & 0.163 & 11.582 & 0.000 & 170 \\
3 & -0.009 & -2.935 & 0.001 & 1.548 & 0.012 & 2.478 & 0.163 & 5.387 & 0.005 & 168 \\
6 & -0.010 & -2.304 & 0.002 & 1.687 & 0.009 & 2.014 & 0.156 & 3.402 & 0.036 & 165 \\
9 & -0.011 & -2.458 & 0.003 & 1.659 & 0.009 & 2.138 & 0.186 & 3.770 & 0.025 & 162 \\
12 & -0.013 & -3.201 & 0.004 & 2.616 & 0.008 & 1.854 & 0.268 & 4.667 & 0.011 & 159 \\
15 & -0.014 & -4.241 & 0.005 & 3.255 & 0.006 & 1.520 & 0.317 & 6.907 & 0.001 & 156 \\
18 & -0.014 & -4.077 & 0.005 & 2.842 & 0.007 & 1.556 & 0.304 & 7.491 & 0.001 & 153 \\
21 & -0.014 & -3.431 & 0.004 & 2.232 & 0.009 & 2.236 & 0.284 & 7.719 & 0.001 & 150 \\
24 & -0.014 & -3.282 & 0.004 & 2.941 & 0.008 & 2.541 & 0.297 & 7.111 & 0.001 & 147 \\
30 & -0.013 & -2.190 & 0.002 & 2.052 & 0.012 & 2.846 & 0.235 & 4.050 & 0.020 & 141 \\
36 & -0.011 & -2.953 & 0.002 & 1.235 & 0.011 & 3.367 & 0.178 & 10.646 & 0.000 & 135 \\
\hline
\end{tabular}

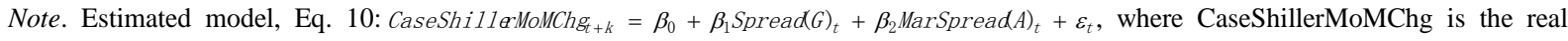
change in the Case-Shiller Index compared with the previous month. Spread $(\mathrm{G})$ is the US government yield spread, defined as the difference between the yield to maturity of a 10-year government bond $\left(\mathrm{Y}(\mathrm{G})_{(10 \mathrm{Yr})}\right)$ and a 3-month government bond $\left(\mathrm{Y}(\mathrm{G})_{(0.25 \mathrm{Yr})}\right)$ and $\operatorname{MarSpread}(\mathrm{A})$ is the marginal corporate yield spread calculated by: MarSpread $A)=\operatorname{TotSpread}(A)-\operatorname{Spread}(G)$

The correlation between $\operatorname{Spread}(\mathrm{G})$ and MarSpread(A) is 0.24 . 
The results in Table 8 are similar to those in the previous regressions, indicating that government and corporate bond spreads can predict monthly changes in housing prices effectively. The results are significant for all forecasted horizons, confirming $\mathrm{H} 2$. As we suggested earlier, the steeper the yield curves are, the higher future housing prices are expected to be. These results are in line with the connection between steeper curves and better future economic growth that increases the disposable income of consumers, enabling them to pay more for housing.

Here too, as in the previous section, we performed an out-of-sample analysis of a linear regression we estimated. Our out-of-sample analysis consists of the last regression for this section, which estimates monthly changes in housing prices. As before, the period from the start of the data until the end of 2010 was defined as the estimation period. The rest of the observations were defined as the prediction period. The out-of-sample analysis for this section is presented in Figure 2.

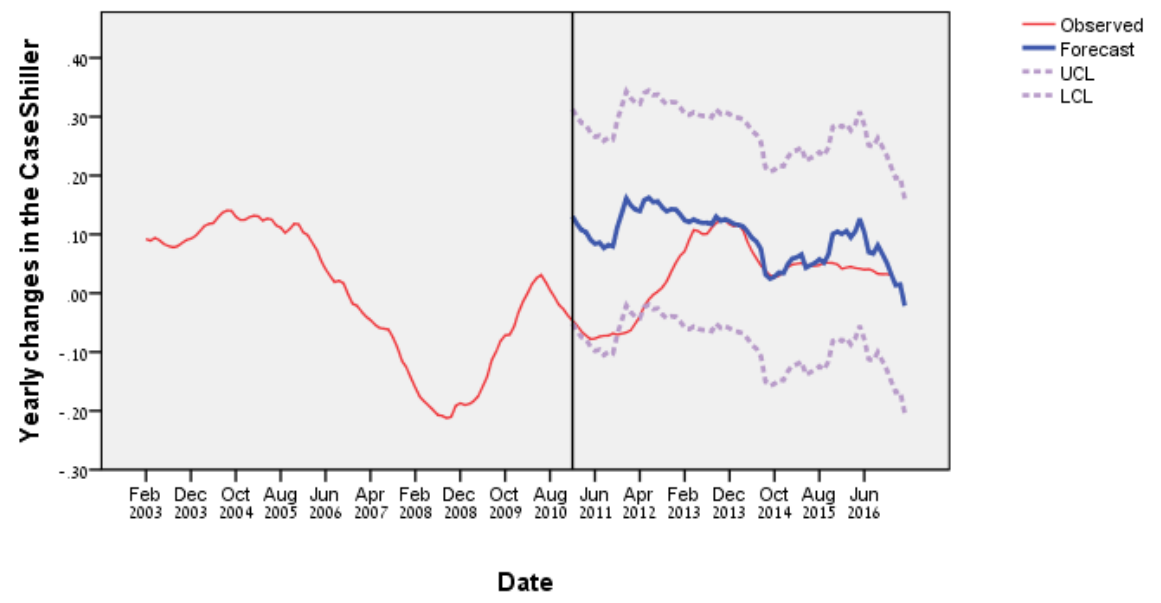

Figure 2. Out-of-sample forecasted yearly changes in the S\&P/case-shiller home prices index based on US government spreads and marginal spreads of A-Rated US corporate bonds, 10/2002 - 12/2016

\begin{tabular}{lcccccc}
\hline & & \multicolumn{2}{c}{ Model Fit statistics } & \multicolumn{2}{c}{ Ljung-Box Q(18) } & \\
\cline { 2 - 5 } Model & Number of Predictors & Stationary R-squared & Statistics & DF & Sig. & Number of Outliers \\
\hline CaseShillerYoYChg & 2 & 0.361 & 764.962 & 18 & 0.000 & 0 \\
\hline
\end{tabular}

Note. The data was divided into an estimation period (10/2002 - 12/2010) and a prediction period (1/2011 - 12/2016). By employing two of the estimated predictors, $\operatorname{Spread}(\mathrm{G})_{3}$ and $\operatorname{MarSpread}(\mathrm{A})_{3}$, we forecasted the expected values for the prediction period, and compared them with the observed values. The RMSE of this comparison is 0.092 .

The out-of-sample analysis provides a very low RMSE indicating its significance, strengthening our notion that the models we present are indeed effective when forecasting housing prices for both the in-sample and out-of-sample predictions.

\section{Can Corporate and Government Yield Curves Predict Changes in Consumption Expenditures?}

We investigate our final question by estimating two regression equations that link the bond spreads to personal consumption, which is a main component of economic growth. We posit that:

H3: Changes in personal consumption can be predicted using the yield spreads of government and corporate bonds.

\subsection{Definitions}

For this section, we define two explained variables. PCEYoYChg is the real percentage change in personal consumption expenditures compared with the corresponding month in the previous year. This variable allows us to check if personal consumption has expanded or shrunk this year. The second variable is PCEMoMChg, which is the real percentage change in personal consumption expenditures compared with the previous month, allowing us to determine whether personal consumption has expanded or shrunk this month.

\subsection{Testing of the Hypothesis: Estimated Equations and Findings for $\mathrm{H} 3$}

Equation 11 uses the spreads on both government and corporate bonds to predict yearly changes in personal consumption. 


$$
\text { PCEYoYChg } g_{t+k}=\beta_{0}+\beta_{1} \operatorname{Spread}(G)_{t}+\beta_{2} \operatorname{MarSpread}(A)_{t}+\varepsilon_{t} .
$$

The results of the regression in Table 9 indicate that both yield curve spreads can forecast future movements in personal consumption, because the regression is significant for most of the forecasting horizons.

Table 9. Predicted yearly changes in personal consumption expenditures based on US government spreads and marginal spreads of A-Rated US corporate bonds, 10/2002 - 12/2016

\begin{tabular}{ccccccccccc}
\hline $\mathrm{k}$ & $\beta_{0}$ & $\mathrm{t}_{\beta 0}$ & $\beta_{1}$ & $\mathrm{t}_{\beta 1}$ & $\beta_{2}$ & $\mathrm{t}_{\beta 2}$ & $\mathrm{R}^{2}$ & $\mathrm{~F}$ & Sig. & $\mathrm{n}$ \\
\hline 1 & 0.015 & 6.905 & -0.004 & -3.654 & 0.019 & 4.782 & 0.175 & 11.913 & 0.000 & 170 \\
3 & 0.011 & 3.096 & -0.003 & -1.687 & 0.022 & 3.317 & 0.205 & 5.587 & 0.004 & 168 \\
6 & 0.007 & 1.212 & -0.001 & -0.462 & 0.024 & 2.659 & 0.238 & 4.022 & 0.020 & 165 \\
9 & 0.003 & 0.325 & 0.001 & 0.638 & 0.022 & 2.184 & 0.252 & 3.041 & 0.051 & 162 \\
12 & 0.000 & -0.046 & 0.004 & 1.418 & 0.019 & 1.765 & 0.280 & 2.529 & 0.083 & 159 \\
15 & -0.001 & -0.124 & 0.005 & 2.092 & 0.014 & 1.385 & 0.287 & 2.401 & 0.094 & 156 \\
18 & -0.003 & -0.235 & 0.007 & 2.570 & 0.010 & 1.194 & 0.341 & 3.500 & 0.033 & 153 \\
21 & -0.003 & -0.331 & 0.008 & 2.680 & 0.008 & 1.071 & 0.384 & 3.746 & 0.026 & 150 \\
24 & -0.004 & -0.511 & 0.008 & 2.626 & 0.006 & 0.877 & 0.431 & 3.738 & 0.026 & 147 \\
30 & -0.004 & -0.644 & 0.008 & 2.374 & 0.007 & 0.836 & 0.430 & 4.446 & 0.013 & 141 \\
36 & -0.002 & -0.233 & 0.005 & 1.758 & 0.013 & 1.311 & 0.307 & 2.208 & 0.114 & 135 \\
\hline
\end{tabular}

Note. Estimated model, Eq. 11: PCEYoYChg $_{+k}=\beta_{0}+\beta_{1} \operatorname{Spread}(G)_{t}+\beta_{2}$ MarSpread $\left.A\right)_{t}+\varepsilon_{t}$, where PCEYoYChg is the real change in personal consumption expenditures compared with the corresponding month in the previous year. $\operatorname{Spread}(\mathrm{G})$ is the US government yield spread, defined as the difference between the yield to maturity of a 10-year government bond $\left(\mathrm{Y}(\mathrm{G})_{(10 \mathrm{Yr})}\right)$ and a 3-month government bond $\left(\mathrm{Y}(\mathrm{G})_{(0.25 \mathrm{Yr})}\right)$ and MarSpread(A) is the marginal corporate yield spread calculated by: $\operatorname{MarSpread}(A)=\operatorname{TotSpread}(A)-\operatorname{Spread}(G)$

The correlation between $\operatorname{Spread}(\mathrm{G})$ and $\operatorname{MarSpread}(\mathrm{A})$ is 0.24 .

As in the previous sections, here too, the marginal corporate bond spread is more efficient in forecasting movements in personal consumption for the short-term, whereas the government bond spread is better at predicting changes in personal consumption in the long-term. In addition, we find a positive relationship between the spreads and future consumption, which is not surprising given that consumption is an important part of economic growth. Previous studies have shown a positive connection between the growth rate and the bond spreads. Our results support these previous findings and also shed more light on the yield curves' ability to forecast future economic behavior. The last regression we estimate in this study is similar to the previous one in which the explained variable is the monthly change in personal consumption:

$$
\text { PCEMoMChg } g_{t+k}=\beta_{0}+\beta_{1} \operatorname{Spread}(G)_{t}+\beta_{2} \operatorname{MarSpread}(A)_{t}+\varepsilon_{t} .
$$

Table 10. Predicted monthly changes in personal consumption expenditures based on US government spreads and marginal spreads of A-Rated US corporate bonds, 10/2002 - 12/2016

\begin{tabular}{ccccccccccc}
\hline $\mathrm{k}$ & $\beta_{0}$ & $\mathrm{t}_{\beta 0}$ & $\beta_{1}$ & $\mathrm{t}_{\beta 1}$ & $\beta_{2}$ & $\mathrm{t}_{\beta 2}$ & $\mathrm{R}^{2}$ & $\mathrm{~F}$ & Sig. & $\mathrm{n}$ \\
\hline 1 & 0.001 & 0.809 & 0.000 & -0.324 & 0.002 & 2.649 & 0.039 & 3.706 & 0.027 & 170 \\
3 & 0.000 & 0.087 & 0.000 & 0.271 & 0.002 & 2.762 & 0.053 & 4.650 & 0.011 & 168 \\
6 & 0.000 & 0.003 & 0.000 & 1.654 & 0.002 & 1.614 & 0.042 & 2.962 & 0.055 & 165 \\
9 & 0.000 & -0.323 & 0.001 & 2.262 & 0.001 & 1.460 & 0.054 & 2.945 & 0.055 & 162 \\
12 & 0.000 & -0.272 & 0.001 & 2.292 & 0.001 & 1.070 & 0.054 & 2.787 & 0.065 & 159 \\
15 & 0.000 & -0.082 & 0.001 & 1.819 & 0.001 & 0.824 & 0.045 & 1.770 & 0.174 & 156 \\
18 & 0.000 & -0.620 & 0.001 & 2.524 & 0.001 & 1.111 & 0.069 & 3.487 & 0.033 & 153 \\
21 & 0.000 & -0.586 & 0.001 & 2.456 & 0.001 & 0.823 & 0.072 & 3.827 & 0.024 & 150 \\
24 & 0.000 & -0.527 & 0.001 & 2.096 & 0.001 & 0.765 & 0.062 & 3.847 & 0.024 & 147 \\
30 & 0.000 & -0.146 & 0.000 & 1.357 & 0.001 & 0.893 & 0.044 & 1.606 & 0.204 & 141 \\
36 & 0.000 & -0.013 & 0.000 & 0.844 & 0.002 & 2.286 & 0.055 & 2.672 & 0.073 & 135 \\
\hline
\end{tabular}

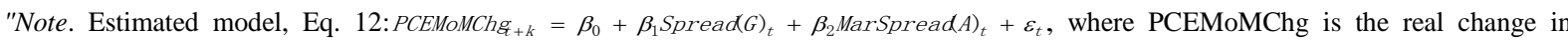
personal consumption expenditures compared with the previous month. $\operatorname{Spread}(\mathrm{G})$ is the US government yield spread, defined as the difference between the yield to maturity of a 10-year government bond $\left(\mathrm{Y}(\mathrm{G})_{(10 \mathrm{Yr})}\right)$ and a 3-month government bond $\left(\mathrm{Y}(\mathrm{G})_{(0.25 \mathrm{Yr})}\right)$ and $\operatorname{MarSpread}(\mathrm{A})$ is the marginal corporate yield spread calculated by: $\operatorname{MarSpread}(A)=\operatorname{Tot} \operatorname{Spread}(A)-\operatorname{Spread}(G)$

The correlation between $\operatorname{Spread}(\mathrm{G})$ and $\operatorname{MarSpread}(\mathrm{A})$ is 0.24 . 
The results of this regression, shown in Table 10, indicate weaker results than those of the previous regression. This result might be due to seasonal changes in consumption. However, in half of the cases the regression is significant, implying that the bond spreads can also predict monthly changes in consumption. When comparing the results of the different sections in this study, another interesting finding emerges. Yield curves are best at forecasting upcoming changes in the unemployment rate and weakest at forecasting changes in personal consumption.

Finally, we performed an out-of-sample analysis for the previous regression, which estimates yearly changes in personal consumption. Here too, we defined the estimation period from the start of the data until the end of 2010. Observations from 2011 to 2016 were defined as the prediction period. The out-of-sample analysis for this section is presented in Figure 3.

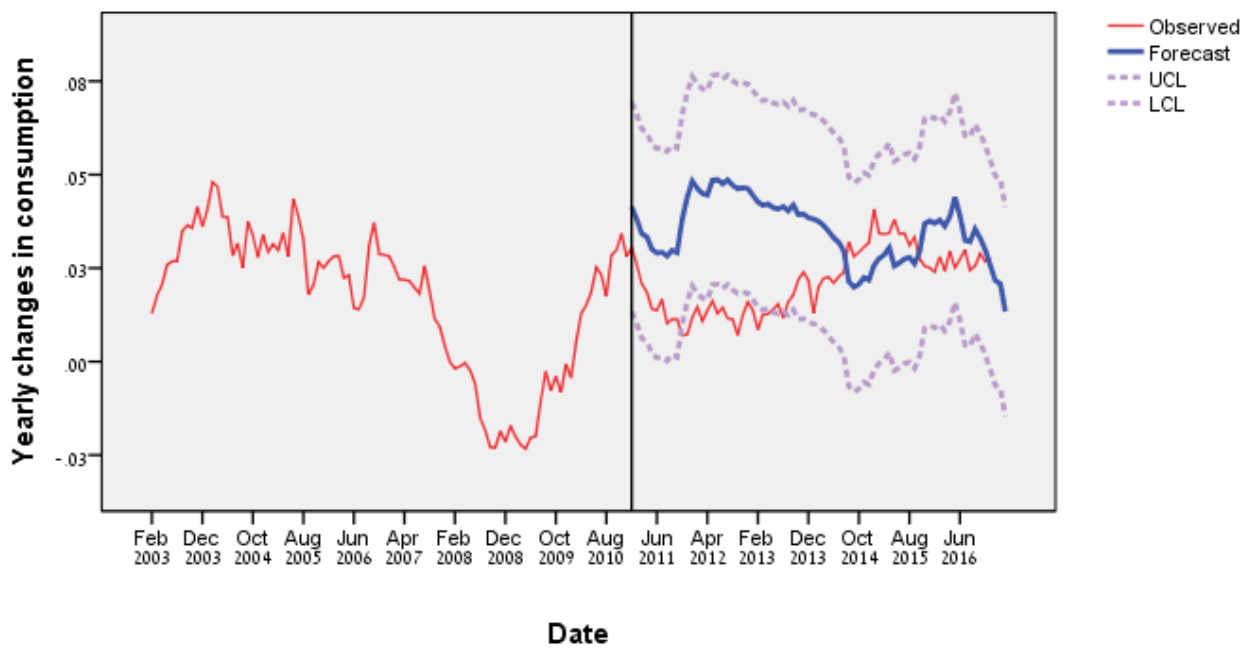

Figure 3. Out-of-sample forecasted yearly changes in personal consumption expenditures based on US government spreads and marginal spreads of A-Rated US corporate bonds, 10/2002 - 12/2016

\begin{tabular}{lcccccc}
\hline & \multirow{2}{*}{$\begin{array}{c}\text { Number of } \\
\text { Model }\end{array}$} & \multicolumn{2}{c}{ Model Fit statistics } & \multicolumn{2}{c}{ Ljung-Box Q(18) } & \\
\cline { 3 - 6 } Predictors & Stationary R-squared & Statistics & DF & Sig. & Number of Outliers \\
\hline PCEYoYChg & 2 & 0.479 & 456.631 & 18 & 0.000 & 0 \\
\hline
\end{tabular}

Note. The data was divided into an estimation period (10/2002 - 12/2010) and a prediction period (1/2011 - 12/2016). By employing two of the estimated predictors, $\operatorname{Spread}(\mathrm{G})_{3}$ and $\operatorname{MarSpread}(\mathrm{A})_{3}$, we forecasted the expected values for the prediction period, and compared them with the observed values. The RMSE of this comparison is 0.014 .

This analysis provides a very low RMSE signaling the significance of the results we obtained in the previous regressions.

Our findings contribute to the understanding that government and corporate bond spreads can forecast specific segments of economic growth such as the unemployment rate, housing prices and personal consumption.

\section{Concluding Remarks}

This study has investigated whether previous findings indicating that the spreads of corporate and government bonds can forecast macroeconomic parameters could be extended to predict the behavior of specific segments of economic growth such as labor market trends, housing prices and personal consumption. While previous studies have succeeded mostly in forecasting broad market indicators like the growth rate and stock market behavior, we suggest that the use of corporate bonds, first used by Saar and Yagil, can enable the prediction of segment specific parts of the growth of the economy.

Using linear and logistic regressions as well as out-of-sample analyses with data about the US economy from 2002 to 2016, we have reached several important conclusions.

First, we find that the spreads of corporate and government bonds can forecast changes in the unemployment rate both on the monthly and yearly level. Moreover, we find a negative relationship between the spreads and changes in unemployment, implying that higher spreads indicate a lower unemployment rate in the future.

When investigating the housing market, we discover a similar although positive relationship between the government and corporate bond spreads and housing prices. The positive relationship stems from the fact that 
rising housing prices are related to an improved economic state accompanied by increased disposable income.

Finally, we tested whether our findings are also relevant for predicting personal consumption. Here too, we establish a positive relationship between the spreads and future personal consumption. However, while the results in this area are significant, they are weaker compared with those of the housing and labor markets.

All of our results were later reaffirmed by conducting out-of-sample analyses which provided us with a different approach to check their relevancy and robustness. One additional finding worth noting is that in line with the previous studies of Saar and Yagil, government bonds are better predictors for the long-term, whereas corporate bonds are better predictors for the short-term. We surmise that these findings result from the fact that investments in government bonds are usually more strategic and long-term as opposed to investments in corporate bonds that are considered to be more tactical.

In sum, by using a vast number of tools, out-of-sample analyses, and a relatively large and up to date sample in order to verify the validity of our results, we can conclude that government and corporate yield spreads can predict future segment specific parts of the growth of the economy such as trends in the labor market, changes in housing prices and personal consumption. One limitation of this study is due to the fact that precise and reliable corporate bonds data has been available only for a period of less than 20 years, and a future possible extension is to incorporate more data points when they become available.

\section{References}

Altman, E. I. (1987). The Anatomy of High-Yield Bond Market. Financial Analysts Journal, 43, 12-25. https://doi.org/10.2469/faj.v43.n4.12

Bar-Isaac, H., \& Shapiro, J. (2013). Ratings quality over the business cycle. Journal of Financial Economics, 108(1), 62-78. https://doi.org/10.1016/j.jfineco.2012.11.004

Berardi, A., \& Torous, W. (2005). Term Structure Forecasts of Long Term Consumption Growth. Journal of Financial and Quantitative Analysis, 40, 241-258. https://doi.org/10.1017/s0022109000002295

Boyd, J. H., Hu, J., \& Jagannatan, R. (2005). The Stock Market's Reaction to Unemployment News: Why Bad News Is Usually Good for Stocks. The Journal of Finance, 60(2), 649-672. https://doi.org/10.1111/j.1540-6261.2005.00742.x

Brandt, M., \& Kavajecz, K. (2004). Price Discovery in the U.S. Treasury Market: The Impact of Orderflow and Liquidity on the Yield Curve. Journal of Finance, 59, 2623-2654. https://doi.org/10.1111/j.1540-6261.2004.00711.x

Chang, K. L., Chen, N. K., \& Leung, C. K. Y. (2011). Monetary Policy, Term Structure and Asset Return: Comparing REIT, Housing and Stock. The Journal of Real Estate Finance and Economics, 43(1), 221-257. https://doi.org/10.1007/s11146-010-9241-8

Chen, L., \& Zhang, L. (2011). Do time-varying risk premiums explain labor market performance? Journal of Financial Economics, 99(2), 385-399. https://doi.org/10.1016/j.jfineco.2010.09.002

Chun, A. L. (2011). Expectations, Bond Yields, and Monetary Policy. Review of Financial Studies, 24, 208-247. https://doi.org/10.1093/rfs/hhq090

Duffee, G. R., \& Hopkins, J. (2011). Information in (and not in) the Term Structure. Review of Financial Studies, 24, 2895-2934.

Duffie, D., \& Singleton, K. (1999). Modeling Term Structures of Defaultable Bonds. Review of Financial Studies, 12, 687-720. https://doi.org/10.1093/rfs/12.4.687

Estrella, A., \& Hardouvelis, G. A. (1991). The Term Structure as a Predictor of Real Economic Activity. Journal of Finance, 46, 555-577. https://doi.org/10.1111/j.1540-6261.1991.tb02674.x

Fabozzi, F. J. (2005). The Handbook of Fixed Income Securities (Vol. 6). New York: McGraw-Hill.

Fons, J. S. (1994). Using Default Rates to Model the Term Structure of Credit Risk. Financial Analysts Journal, 50, 25-32. https://doi.org/10.2469/faj.v50.n5.25

Goyenko, R., Subrahmanyam, A., \& Ukhov, A. (2011). The Term Structure of Bond Market Liquidity and Its Implications for Expected Bond Returns. Journal of Financial and Quantitative Analysis, 46(1), 111-139. https://doi.org/10.1017/s0022109010000700

Harvey, C. R. (1998). The real term structure and consumption growth. Journal of Financial Economics, 22(2), 305-333. 
Helwege, J., \& Turner, C. M. (1999). The Slope of Credit Yield Curve for Speculative-Grade Issuers. Journal of Finance, 54, 1869-1884. https://doi.org/10.1111/0022-1082.00170

Huang, J. Z., \& Huang, M. (2012). How Much of the Corporate-Treasury Yield Spread Is Due to Credit Risk? The Review of Asset Pricing Studies, 2(2), 153-202. https://doi.org/10.1093/rapstu/ras011

Jarrow, R., Lando, D., \& Turnbull, S. (1997). A Markov Model for the Term Structure of Credit Spreads. Review of Financial Studies, 10, 481-523. https://doi.org/10.1093/rfs/10.2.481

Kau, J. B., \& Keenan, D. (1980). The theory of housing and interest rates. Journal of Financial and Quantitative Analysis, 15, 833-847.

Kim, D. H., \& Orphanides, A. (2012). Term Structure Estimation with Survey Data on Interest Rate Forecasts. Journal of Financial and Quantitative Analysis, 47, 241-272. https://doi.org/10.1017/s0022109011000627

Lettau, M., \& Wachter, J. A. (2011). The Term Structures of Equity and Interest Rates. Journal of Financial Economics, 101, 90-113.

Papell, D. H., Murray, C. J., \& Ghiblawi, H. (2000). The structure of unemployment. Review of Economics and Statistics, 82(2), 309-315.

Piazzesia, M., Schneidra, M., \& Tuzelb, S. (2007). Housing, consumption and asset pricing. Journal of Financial Economics, 83(3), 531-569. https://doi.org/10.1016/j.jfineco.2006.01.006

Saar, D., \& Yagil, Y. (2015a). Forecasting sectorial profitability and credit spreads using bond yields. International Review of Economics \& Finance, 38(C), 29-43. https://doi.org/10.1016/j.iref.2014.12.009

Saar, D., \& Yagil, Y. (2015b). Forecasting growth and stock performance using government and corporate yield curves: Evidence from the European and Asian markets. Journal of International Financial Markets, Institutions and Money, 37(C), 27-41. https://doi.org/10.1016/j.intfin.2015.04.002

Saar, D., \& Yagil, Y. (2015c). Corporate yield curves as predictors of future economic and financial indicators. Applied Economics, 47(19), 1997-2011. https://doi.org/10.1080/00036846.2014.1002898

Stevenson, H. W., \& Pellatt, P. G. K. (1972). The analysis of real estate investments under uncertainty. Journal of Finance, 27(2), 459-471. https://doi.org/10.2307/2978488

Wachter, J. A. (2006). A consumption-based model of the term structure of interest rates. Journal of Financial Economics, 79(2), 365-399. https://doi.org/10.1016/j.jfineco.2005.02.004

Zhou, C. (2001). The Term Structure of Credit Spreads With Jump Risk. Journal of Banking and Finance, 25, 2015-2040. https://doi.org/10.1016/s0378-4266(00)00168-0

\section{Copyrights}

Copyright for this article is retained by the author(s), with first publication rights granted to the journal.

This is an open-access article distributed under the terms and conditions of the Creative Commons Attribution license (http://creativecommons.org/licenses/by/4.0/). 